certain number of patients, being moribund at the time of their arrival and beyond the reach of any treatment, no antitoxin was given."

I am, Sirs, yours faithfully,

Iansfield-street, W., July 21st, 1896 . LENToX Browne.

\section{THE HEALTH OF MARGATE.}

To the Editors of THE LANCET.

SIRS,-It having come to my knowledge that a rumour has been circulated that several cases of typhoid fever have recently occurred in Margate I shall be obliged if you will kindly give me the opportunity to contradict it. The date of the last notification of this disease in this borough was over two months ago-viz., on May 15th, 1896. This, moreover, was an isolated case, no other having occurred about the same time, and it was immediately removed to our infectious diseases hospital, which is sitnated about two and a half miles out of the town.

I am, Sirs, yours very truly,

Margate, July 21st, 1896.

A. W. SCATLIFF Medical Officer of Health.

\section{THE INVERNESS MEDICAL SOCIE'TY.}

To the Editors of THE LANCET.

StRS, - In THE LANCET of July 18th your Inverness correspondent, reporting the proceedings of the Inverness Medical Society, has the following: "The club question came up for discussion at several meetings and the members were unanimous in refusing to undertake club work unless the scale of rates were in accordance with that suggested by the society. The clubs did not see their way to agree to this arrangement and the medical officers resigned. The clubs in town joined together and advertised for a medical officer to undertake the work at their terms. Unfortunately for the credit of the profession a medical gentleman, Dr. Callender, formerly of Leeds, accepted the position, thus frustrating the efforts of the society in their endeavour to place the relations of the medical practitioners in Inverness and the clubs on a better financial basis than they had been hitherto." These sentences, in so far as they relate to the united clubs in Inverness and their medical officer, are false. The united clubs gave up their old terms and adopted simpliciter the scale of rates suggested by the medical society. The clubs unanimously elected $\mathrm{Dr}$. Callender as their medical officer, and he holds the appointment at the scale of rates suggested by the medical society. Dr. Moir, secretary to the Inverness Medical Society, knew these facts six months ago. "Unfortunately for the credit of the medical profession" your Inverness correspondent has given a statement to you which (at any time during the last six months he had ample opportunity to find out) is false.

\section{We are, Sirs, yours truly,}

J. CALLENDER,

Medical Officer ;

JAMES CORNET,

Inverness, July 20th, 1896.

Hon. Sec. Committee of Combined Clubs.

\section{"A UNIQUE EXPERIENCE IN ETHER ADMINISTRATION."}

To the Editors of THE LANCET.

SIRS,-I was interested in reading the report of this case in THE LANCEN of July 11th, as I have been noticing for the last two years how little ether need be used to keep a patient fully anæsthetised. In an article on ether administration which appeared in the Bristol Medico-Chirurgical Journal of September, 1895, I stated that nearly all patients when once fully under with ether could be kept so with the indicator of Clover's apparatus midway between " 0 " and "1." I never find it necessary to keep the indicator at " 2 ," as some books recommend, and I frequently succeed in maintaining complete anæsthesia for more than half an hour at a time with the indicator at "0." I quite agree with Dr. Carter that such cases show "how much more ether is frequently given than is necessary."

I am, Sirs, yours truly,

J. FREEMAN, F.R.C.S. Ed.

Bristol, Juily 19th, 1896 .

\section{"THE REMUNERATION OF MEDICAL MIEN."} To the Editors of THE LANCET.

SIRS, - The inadequate remuneration of medical men depends, I think, on two sets of causes: (1) those acting from without and which in the present state of things seem incapable of amelioration; and (2) those acting from within, from the conduct of medical men themselves. Among the first set of causes of ill-remuneration may be mentioned overcrowding of the profession, the multitudinous array of pestilent quacks, the ignoble army of patent medicine vendors with their cmnipotent wares, and the counterprescribing druggists mentioned by " $\mathrm{H}$. C. L." in THE LANCET of July 4th. The district in which I live has lately been infested by quack cataract-without-operation curers, magic belt bouncers, and the ubiquitous Esculapii of the Sequah type. With regard to patent medicines, bold advertisement and the fact of a Government stamp being affixed to each bottle or box account for their huge sale. The public imagine that what is stamped in this way must be genuine. It is astonishing how widespread the use of patent medicines is amongst all classes of the community. There is hardly a household in Great Britain which does not possess a box of magic pills or some other equally beneficent remedy. In the most well-to.do houses I have seen the wellknown electricities of a certain deceased nobleman. An ounce of these costs $3 s .9 d$. - an exorbitant price for pure water. Nothing can put a stop to this scrt of thing except the refusal of newspapers to publish quack advertisements, but these halcyon days can hardly be looked for. Counter prescribing is a serious evil and should be put down with a strong hand, and the most serious aspect of it is that druggists in many cases prescribe without sfeing the "patient" at all. A friend or relative (generally a female) comes to the shop, details the symptoms to the best of ber ability, clutches the remedy, and marches off. Can anything be more dangerous and idiotic? Druggists say that medical men invade their province by making up their own medicines, but they seem to ignore the fact that there is a vast difference between themselves and medical men in the matter of clinical knowledge and the faculty of diagnosing disease When a medical man makes up his medicine he does so with an intelligent and scientific object, which is more than can be said for the druggist, who is simply an empiric, as his medical knowledge is nil. Another favourite device of the ordinary druggist is to make up and advertise stock remedies evolved from his own brain for certain diseases: Quackem's Elixir for Coughs and Colds : invaluable in Bronchitis, \&c. In many of these "chest mixtures" I am afraid there is opium, and the danger of administering these to old people suffering from bronchitis may be imagined. Verily, "fools step in where angels fear to tread." But druggists are not wholly to blame. In these days so many cheap manuals on self-doctoring and newspaper articles on medical subjects are published that the public are beginning to think they can diagnose their own diseases, and they simply apply to the druggist for the remedies recommended in these publications. As to the second set of causes, arising from the conduct of medical men themselves, much might be said, but there is one line of conduct which is becoming commoner every day-i.e., under-cutting one's neighbour in the matter of fees. This, of course, may arise from the terrible struggle for existence, but in many cases it is simply an underhand way of increasing a practice at the expense of a medical brother, as it is done in the case of well-to-do patients every day. What is the remedy for this kind of thing? A universal tariff of minimum charges should be established and every medical man should be bound not to charge less than these. Again, large numbers of medical men are let loose on the public every year who have no idea of medical etiquette or of their duty towards their neighbour, and who will filch a patient by any means, however unfair, and can see no harm in so doing. I think medical students should have special lectures on medical etiquette and their duties to their neighbour, and should give some guarantee before launching into practice that they will faithfully abide, so far as possible, by the rules of honour and probity laid down for their guidance. The status of the profession can also be ameliorated by raising the standard of general knowledge and culture before allowing students to begin their special medical studies. I have said nothing about the harm done 